\title{
COVID-19 during pregnancy should we really worry from vertical transmission or rather from fetal hypoxia and placental insufficiency? A systematic review and meta -analysis
}

\author{
Antoine AbdelMassih ( $\nabla$ antoine.abdelmassih@kasralainy.edu.eg ) \\ Pediatric Cardiology unit, Pediatrics' Department, Faculty of Medicine, Cairo University

\section{Raghda Fouda} \\ University of Irvine
}

Rana Essam

Neonatology unit, Pediatrics' Department, Faculty of Medicine, Cairo University

Alhussein Negm

Student and Internship research program (Research Accessibility Team), Faculty of Medicine, Cairo University

\section{Dalia Khalil}

Student and Internship research program (Research Accessibility Team), Faculty of Medicine, Cairo University

Dalia Habib

Residents' Training program, Faculty of Medicine, Cairo University

\section{George Afdal}

Student and Internship research program (Research Accessibility Team), Faculty of Medicine, Cairo University

\section{Habiba-Allah Ismail}

Student and Internship research program (Research Accessibility Team), Faculty of Medicine, Cairo University

\section{Hadeer Aly}

Student and Internship research program (Research Accessibility Team), Faculty of Medicine, Cairo University Ibrahim Genedy

Student and Internship research program (Research Accessibility Team), Faculty of Medicine, Cairo University

Layla El Qadi

Student and Internship research program (Research Accessibility Team), Faculty of Medicine, Cairo University

Leena Makki

Student and Internship research program (Research Accessibility Team), Faculty of Medicine, Cairo University

\section{Maha Shulqamy}

Student and Internship research program (Research Accessibility Team), Faculty of Medicine, Cairo University

Maram Hanafy

Student and Internship research program (Research Accessibility Team), Faculty of Medicine, Cairo University

\section{Marian AbdelMassih}

Pediatrics, 6th October University

\section{Marina Ibrahim}

Residents' Training program, Faculty of Medicine, Cairo University

Mohamed Ebaid

Student and Internship research program (Research Accessibility Team), Faculty of Medicine, Cairo University

\section{Monica Ibrahim}

Residents' Training program, Faculty of Medicine, Cairo University

\section{Nadine El-Husseiny}

Faculty of Dentistry, Cairo University

Nirvana Ashraf

Student and Internship research program (Research Accessibility Team), Faculty of Medicine, Cairo University Noura Shebl

Student and Internship research program (Research Accessibility Team), Faculty of Medicine, Cairo University

Rahma Menshawey

Student and Internship research program (Research Accessibility Team), Faculty of Medicine, Cairo University 


\section{Rama Darwish}

Student and Internship research program (Research Accessibility Team), Faculty of Medicine, Cairo University

\section{Rana ElShahawi}

Student and Internship research program (Research Accessibility Team), Faculty of Medicine, Cairo University

\section{Rana Ramadan}

Student and Internship research program (Research Accessibility Team), Faculty of Medicine, Cairo University

\section{Sadra Albala}

Student and Internship research program (Research Accessibility Team), Faculty of Medicine, Cairo University

Salwa Imran

Residents' Training program, Faculty of Medicine, Cairo University

\section{Sama Ahmed}

Student and Internship research program (Research Accessibility Team), Faculty of Medicine, Cairo University

Samer Khaldi

Student and Internship research program (Research Accessibility Team), Faculty of Medicine, Cairo University

Sara Abohashish

Student and Internship research program (Research Accessibility Team), Faculty of Medicine, Cairo University

\section{Stavro Paulo}

Student and Internship research program (Research Accessibility Team), Faculty of Medicine, Cairo University

Yasmin Omar

Student and Internship research program (Research Accessibility Team), Faculty of Medicine, Cairo University

Mourad Alfy Tadros

Military Medical College, Royal College of Pediatrics and Child health

\section{Systematic Review}

Keywords: COVID-19, Neonatal outcome, Placental infarctions, Fetal hypoxia, vertical transmission

Posted Date: September 8th, 2020

DOI: https://doi.org/10.21203/rs.3.rs-71847/v1

License: (c) (7) This work is licensed under a Creative Commons Attribution 4.0 International License. Read Full License 


\section{Abstract}

\section{Background:}

COVID-19 is the largest outbreak to strike humanity. The wide scale of fatalities and morbidities lead to a concurrent pandemic of uncertainty in scientific evidence. Conflicting evidences are released on daily basis about the neonatal outcomes of COVID-19 positive mothers. The aim of this study was to use the relevant case reports and series to determine the percentage of newborns who test positive in COVID-19 positive mothers. Secondary outcomes included examining laboratory and placental abnormalities among fetus-mother pairs.

\section{Methods:}

Systematic review was performed on all studies reporting primary data on fetus-mother pairs with COVID-19. Data bases were searched for studies that met our inclusion and exclusion criteria.

\section{Results:}

Final screening revealed 66 studies, from which the primary data of 1787 mother-infant pairs was obtained. Only $2.8 \%$ of mother infant pairs were tested positive, and this finding is identical to percentages reported in former coronaviridae outbreaks. Whereas, $20 \%$ manifested with intrauterine hypoxia alongside placental abnormalities suggestive of heavy placental vaso-occlusive involvement.

\section{Conclusions:}

These findings suggest that while vertical transmission is unlikely, there appears to be an underlying risk of placental insufficiency due to the prothrombotic tendency observed in COVID-19 infection. Guidelines for proper prophylactic anticoagulation in COVID positive mothers need to be established.

\section{Background}

COVID-19 (Coronavirus disease 2019), which has been declared a pandemic in March 2020, has caused an unpreceded uncertainty within the scientific community. Contradictory scientific evidences are released almost every day, on every aspect of the pandemic from its pathogenesis, to the methods of transmission, and to the possible compassionate use of medications to combat it. Transplacental transmission of COVID19 , is one of the topics that have raised conflicting evidences across the globe. The dilemma about transplacental transmission of coronaviridae is not exclusive to the current outbreak. To our knowledge, nine studies ${ }^{1-10}$ from SARS-1 (Severe Acute Respiratory syndrome) and HKCoV (Hong Kong Coronavirus) and MERS (Middle East Respiratory syndrome) outbreaks were reported; ranging from case reports to retrospective case reviews, comprising 71 mother-infant pairs. Table 1 summarizes the findings of the nine studies. Two cases only have shown vertical transmission, a remarkable finding was the strong evidence in those reports of intrauterine fetal hypoxia possibly due to placental damage or even direct evidence of placental infarctions. Gagnueur et al ${ }^{6}$ reported two cases of still birth that was preceded by fetal heart deceleration, whereas, Wong et al and Jeong et al demonstrated placental infarction in three cases. The vascular tropism of COVID-19 has recently gained so much interest, and many of its multi-organ manifestations has been attributed to its endothelial tropism. Such endothelial tropism is accounted for by the high load of Angiotensin Converting Enzyme 2 (ACE2) and Furin, ${ }^{11,12}$ which are important viral checkpoints, in the endothelium. Placenta is a vascular organ, whereby Furin play an important role in its differentiation, moreover, ACE2 and Angiotensin 1-7 are heavily expressed in the placenta, making the placenta an important target for the vascular tropic effect of COVID-19. As mentioned earlier, the number of conflicting evidences regarding vertical transmission of COVID-19 and the effect of maternal COVID-19 on newborns and their placenta, renders systematic review of the clustered cases available of utmost importance to build stronger evidence the neonatal outcomes of COVID-19. The primary outcome parameter of this systematic review is the percentage of newborns testing positive to COVID-19 mothers, while secondary outcome parameters included the assessment of laboratory abnormalities among COVID-19 mothers, and the placental abnormalities encountered in COVID-19 mothers.

\section{Methods}

This systematic review has been conducted in agreement with the guidelines of the PRISMA Statement (Preferred Reporting Items for Systematic Reviews and Meta-Analysis). ${ }^{13}$

\section{>Data Search}

A computer run has been performed EMBASE, Medline and the Cochrane Central Register (From $1^{\text {st }}$ November 2019 to $1^{\text {st }}$ of August 2020 ). The following terms were included in the search: "COVID-19" OR "SARS-CoV-2" (Severe Acute Respiratory syndrome Coronaviridae 2) AND "Pregnancy" AND "Perinatal”. 


\section{>Study Selection criteria}

Population: Pregnant women

Intervention: COVID-19

Comparison: No comparison has been a purpose of the study

Outcome: Neonatal infection by COVID-19, placental abnormalities, laboratory abnormalities in the newborn.

Observational epidemiological studies and case reports addressing the clinical conditions of Mother-fetus pairs. Primary data of patients over 18 years old were considered eligible. Manuscripts that contained only data from pregnant women, or only fetuses, or that did not address the period of delivery, such as puerperium, were disregarded. All data from eligible studies were extracted by 2 independent investigators according to a standard protocol.

\section{Statistical Analysis:}

Each of the maternal manifestations, neonatal manifestations, placental microscopic and macroscopic changes and laboratory changes in COVID-19 positive newborns was quantified and expressed as number $(\mathrm{n})$ and percentages.

\section{Results}

The literature search identified initially 114 studies, of which 44 studies were excluded, 20 were excluded as they did not tackle the primary outcome parameter of the study. While 24 studies were excluded due to repetition. Total number of studies included was 66 studies, comprising 1787 Mother-infant pair. ${ }^{14-80}$

The studies included were listed in Table 2, by alphabetical order of the country of origin.

Table 3 summarizes the clinical manifestations of included COVID-19 positive mothers and the subsequent percentage of positive newborns. Out of 1787 mother-infant pairs, only 49 tested positive (2.8\%), which is surprisingly identical to the percentage of neonates affected in the reported cases series during the previous three outbreaks caused by Coronaviridae, 2/71 (2.8\%) (Table 1). Most of the affected neonates were asymptomatic (24\%). The commonest array of manifestations was those suggestive of intrauterine hypoxia (20\%). The sampling time was not reported in $31 \%$ of cases which is a non-negligible number putting a huge risk of reporting bias. $42 \%$ of positive newborn were tested in the first 12 hours after delivery while the remainder $27 \%$ of cases were tested after 12 hours, raising suspicion of possible postnatal infection.

Table 4 outlines the placental abnormalities in COVID-19 positive mothers. Placental infarction, an evidence of vascular compromise of the villi, was observed in a significant number of abnormal placentae (44\%\%). A lower percentage of positive swabs was retrieved from abnormal placentae accounting for $37 \%$ of all abnormal placentae, and $5 \%$ of all examined placentae. A closer percentage of placental infarctions was observed in placentae examined from the previous outbreak.

Table 5 shows the laboratory abnormalities in COVID-19 positive neonates, the commonest laboratory abnormality in affected neonates is Lymphopenia encountered in $20 \%$ of cases.

\section{Discussion}

Vertical transmission of COVID-19 follows the same pattern of uncertainty as almost everything concerning COVID-19. New evidences being unraveled everyday make meta-analysis the only possible solution to reach consensus about points of dilemma.

This report is by far the largest systematic review to be implemented in this context, not only regarding the number of mother-infant pairs, but also the targeted outcome parameters. The largest report preceding us is De Sousa et al report ${ }^{81}$.

Our study confirmed the previous impression from the former outbreaks by CoV that transplacental transmission is very unlikely occurring in $2.8 \%$ of all positive mothers. A report by Wang and colleagues ${ }^{82}$ suggested that viremia is reported to occur in less than $1 \%$ of cases. However, this finding seems to hugely underestimate the burden of viremia in Coronaviridae infections. An old report by Chen et al ${ }^{83}$ during first SARS outbreak showed that RNA of SARS-CoV can be detected in up to $50 \%$ of blood samples and can last up to one week.

The commonest laboratory finding in affected neonates was Lymphopenia. This finding goes in agreement with the same pattern of hematologic abnormalities encountered in adult patients. The Programmed cell death receptor 1 secreted from macrophages in the lung environment as well as from resident T cells leads finally to T cell exhaustion with subsequent Lymphopenia encountered affected patients.

Page $4 / 15$ 
The most intriguing finding uncovered in our series is the strong evidence pointing towards placental damage with subsequent intrauterine hypoxia of the fetus. This finding was supported at several stages in our study. As mentioned earlier, $20 \%$ of all infants in whom manifestations have been reported have showed evidence of intrauterine hypoxia. Seven percent of all patients were born preterm due to evidence of fetal deceleration that necessitated pregnancy termination. Histopathological changes of placenta offered a strong reason for the observed neonatal manifestations. Placental changes were more prevalent than COVID-19 positive neonates, 46 vs. 45 respectively, out of which $44 \%$ showed evidence of ischemia. Placental changes encountered seemed to mirror the timeline at which infection was detected in COVID-19 positive mothers. $3 \%$ of mothers were infected in the $1^{\text {st }}$ trimester, while defective proliferation and formation of villi was observed in a similar percentage of cases.

Defective formation of villi can be accounted due to the role played by an intracellular enzyme termed Furin in the genesis of placental villi. ${ }^{84-}$

${ }^{86}$ AbdelMassih outlined the important interplay between Furin, COVID-19, and the vascular endothelium; an important constituent of the human placenta.

In view of the above findings, proper hydration and prophylactic anticoagulation should be provided for COVID-19 pregnant women, especially those whose tests suggests strong prothrombotic tendency such elevated D-Dimer, or those whose abdominal ultrasound and fetal cardiotocography offer a strong evidence of placental insufficiency. The guidelines of several Obstetrics and gynecological international societies were clustered by D'Souza et al, and went in agreement with our suggestions. ${ }^{87}$

\section{Conclusion}

The aggregated data in this systematic review are by far the largest to date regarding neonatal outcomes of COVID-19. Results suggest that vertical transmission of COVID-19 is unlikely but underlines an important and underestimated risk, which is placental insufficiency due to the prothrombotic tendency created by COVID-19. These findings should warrant all Ob/Gyn societies across the world about establishing guidelines for safe prophylactic anticoagulation in COVID-19 positive mothers

\section{Abbreviations}

- ACE2: Angiotensin Converting Enzyme 2

- CNS: Central Nervous System

- COVID-19: Coronavirus disease 19

- GA: Gestational Age

- GERD: Gastro-oesophageal Reflux Disease

- GIT: Gastro-intestinal System

- HKCoV: Hong Kong Coronavirus

- IUGR: Intrauterine Growth Retardation

- MERS: Middle East Respiratory Syndrome

- $\mathrm{N}$ : number

- NEC: Necrotizing Enterocolitis

- Ob/Gyn: Obstetrics and Gynaecology

- PRISMA Statement: Preferred Reporting Items for Systematic Reviews and Meta-Analysis

- RDS: Respiratory Distress Syndrome

- SARS-1: Severe Acute Respiratory Syndrome

- W: weeks

\section{Declarations}

\section{Ethics approval and consent to participate}

Not applicable

\section{Consent for publication}

Not Applicable 
Availability of data and material

Not applicable

\section{Competing interests}

The authors declare that they have no competing interests

\section{Funding}

This research received no specific grant from any funding agency, commercial or not-for-profit sectors

\section{Authors' contributions}

AA, LE, MA, MT contributed to the conception and design of the work

$\mathrm{RF}, \mathrm{RE}, \mathrm{DH}, \mathrm{DK}, \mathrm{YO}, \mathrm{SA}^{3}, \mathrm{MI}^{1}, \mathrm{Ml}^{2}$ contribute significantly to the acquisition of data

$\mathrm{HA}, \mathrm{HI}, \mathrm{AN}, \mathrm{GA}, \mathrm{IG}, \mathrm{LM}, \mathrm{MS}, \mathrm{MH}, \mathrm{ME}, \mathrm{NE}, \mathrm{NA}, \mathrm{NS}, \mathrm{RD}, \mathrm{RS}, \mathrm{RR}, \mathrm{SA}^{1}, \mathrm{SI}, \mathrm{SA}^{2}$, SK, SP contributed to the analysis and interpretation of data

R.M contributed to the drafting and revision of the manuscript

All authors have approved the submitted version

All authors have agreed both to be personally accountable for the author's own contributions and to ensure that questions related to the accuracy or integrity of any part of the work, even ones in which the author was not personally involved, are appropriately investigated, resolved, and the resolution documented in the literature.

NB: Due to identical initials of some authors we used superscript to define authors with identical initials as follows:

MIㄴ: Marina Ibrahim, MI²: Monica Ibrahim. SA ${ }^{1}$ : Sadra Albala, SA ${ }^{2}$ : Sama Ahmed, SA ${ }^{3}$ : Sara Abohashish

\section{Acknowledgements}

To our families who are bearing the weight of our sacrifice of time to our patients. If our families were not understanding to the depth of our struggle, we would have never been able to keep the same level of dedication to our patients. To our students that we involve in each step of our researches to make them flourish in this field and take the lead the soonest the possible.

\section{References}

1. Jeong, S. Y. et al. MERS-CoV infection in a pregnant woman in Korea. J. Korean Med. Sci. 32, 1717-1720 (2017).

2. Payne, D. C. et al. Stillbirth During Infection With Middle East Respiratory Syndrome Coronavirus. J. Infect. Dis. 209, 1870-1872 (2014).

3. Wong, S. F. et al. Pregnancy and perinatal outcomes of women with severe acute respiratory syndrome. Am. J. Obstet. Gynecol. 191, 292297 (2004).

4. Yudin, M. H. et al. Severe Acute Respiratory Syndrome in Pregnancy. Obstet. Gynecol. 105, 124-127 (2005).

5. Stockman, L. J., Lowther, S. A., Coy, K., Saw, J. \& Parashar, U. D. SARS during pregnancy, United States [2]. Emerging Infectious Diseases (2004). doi:10.3201/eid1009.040244

6. Gagneur, A. et al. Materno-fetal transmission of human coronaviruses: a prospective pilot study. Eur. J. Clin. Microbiol. Infect. Dis. 27, 863-866 (2008).

7. Li, A. M. Severe acute respiratory syndrome (SARS) in neonates and children. Arch. Dis. Child. - Fetal Neonatal Ed. 90, F461-F465 (2005).

8. Shek, C. C. et al. Infants born to mothers with severe acute respiratory syndrome. Pediatrics 112, (2003).

9. Jeong, S. Y. et al. MERS-CoV Infection in a Pregnant Woman in Korea. J. Korean Med. Sci. 32, 1717 (2017).

10. Robertson, C. A. et al. SARS and Pregnancy: A Case Report. Emerg. Infect. Dis. 10, 345-348 (2004).

11. Li, M., Chen, L., Xiong, C., Li, X. \& Hospital, F. The ACE2 expression of maternal-fetal interface and fetal organs indicates potential risk of vertical transmission of SARS-COV-2.

12. AbdelMassih, A. F. et al. A multicenter consensus: A role of furin in the endothelial tropism in obese patients with COVID-19 infection. Obesity Medicine (2020). doi:10.1016/j.obmed.2020.100281 
13. Moher, D., Liberati, A., Tetzlaff, J. \& Altman, D. G. Preferred reporting items for systematic reviews and meta-analyses: the PRISMA statement. J. Clin. Epidemiol. (2009). doi:10.1016/j.jclinepi.2009.06.005

14. Khan, S. et al. Association of COVID-19 with pregnancy outcomes in health-care workers and general women. Clinical Microbiology and Infection (2020). doi:10.1016/j.cmi.2020.03.034

15. Hantoushzadeh, S. et al. Maternal death due to COVID-19. Am. J. Obstet. Gynecol. (2020). doi:10.1016/j.ajog.2020.04.030

16. Chen, S. et al. Clinical analysis of pregnant women with 2019 novel coronavirus pneumonia. J. Med. Virol. (2020). doi:10.1002/jmv.25789

17. Chen, R. et al. Safety and efficacy of different anesthetic regimens for parturients with COVID-19 undergoing Cesarean delivery: a case series of 17 patients. Can. J. Anesth. (2020). doi:10.1007/s12630-020-01630-7

18. Ferrazzi, E. et al. Vaginal delivery in SARS-CoV-2-infected pregnant women in Northern Italy: a retrospective analysis. BJOG An Int. J. Obstet. Gynaecol. (2020). doi:10.1111/1471-0528.16278

19. Dashraath, P. et al. Coronavirus disease 2019 (COVID-19) pandemic and pregnancy. Am. J. Obstet. Gynecol. (2020). doi:10.1016/j.ajog.2020.03.021

20. Baud, D. et al. Second-Trimester Miscarriage in a Pregnant Woman with SARS-CoV-2 Infection. JAMA - Journal of the American Medical Association (2020). doi:10.1001/jama.2020.7233

21. Dong, L. et al. Possible Vertical Transmission of SARS-CoV-2 from an Infected Mother to Her Newborn. JAMA - Journal of the American Medical Association (2020). doi:10.1001/jama.2020.4621

22. González Romero, D., Ocampo Pérez, J., González Bautista, L. \& Santana-Cabrera, L. Pregnancy and perinatal outcome of a woman with COVID-19 infection. Revista Clinica Espanola (2020). doi:10.1016/j.rce.2020.04.006

23. Breslin, N. et al. Coronavirus disease 2019 infection among asymptomatic and symptomatic pregnant women: two weeks of confirmed presentations to an affiliated pair of New York City hospitals. Am. J. Obstet. Gynecol. MFM (2020). doi:10.1016/j.ajogmf.2020.100118

24. Alzamora, M. C. et al. Severe COVID-19 during Pregnancy and Possible Vertical Transmission. Am. J. Perinatol. (2020). doi:10.1055/s0040-1710050

25. Chen, H. et al. Clinical characteristics and intrauterine vertical transmission potential of COVID-19 infection in nine pregnant women: a retrospective review of medical records. Lancet (2020). doi:10.1016/S0140-6736(20)30360-3

26. Qiancheng, X. et al. Coronavirus disease 2019 in pregnancy. Int. J. Infect. Dis. (2020). doi:10.1016/j.jjid.2020.04.065

27. Liu, Y., Chen, H., Tang, K. \& Guo, Y. Clinical manifestations and outcome of SARS-CoV-2 infection during pregnancy. The Journal of infection (2020). doi:10.1016/j.jinf.2020.02.028

28. Liao, X., Yang, H., Kong, J. \& Yang, H. Chest CT Findings in a Pregnant Patient with 2019 Novel Coronavirus Disease. Balkan Med. J. (2020). doi:10.4274/balkanmedj.galenos.2020.2020.3.89

29. Yu, N. et al. Clinical features and obstetric and neonatal outcomes of pregnant patients with COVID-19 in Wuhan, China: a retrospective, single-centre, descriptive study. Lancet Infect. Dis. (2020). doi:10.1016/S1473-3099(20)30176-6

30. Kirtsman, M. et al. Probable congenital sars-cov-2 infection in a neonate born to a woman with active sars-cov-2 infection. CMAJ (2020). doi:10.1503/cmaj.200821

31. Kang, X. et al. Anesthesia management in cesarean section for a patient with coronavirus disease 2019. Zhejiang Da Xue Xue Bao. Yi Xue Ban (2020).

32. Buonsenso, D. et al. Clinical role of lung ultrasound for diagnosis and monitoring of COVID-19 pneumonia in pregnant women. Ultrasound Obstet. Gynecol. (2020). doi:10.1002/uog.22055

33. Lu, D. et al. Asymptomatic COVID-19 infection in late pregnancy indicated no vertical transmission. J. Med. Virol. (2020). doi:10.1002/jmv.25927

34. Khan, S. et al. Impact of COVID-19 infection on pregnancy outcomes and the risk of maternal-to-neonatal intrapartum transmission of COVID-19 during natural birth. Infection Control and Hospital Epidemiology (2020). doi:10.1017/ice.2020.84

35. Kalafat, E. et al. Lung ultrasound and computed tomographic findings in pregnant woman with COVID-19. Ultrasound Obstet. Gynecol. (2020). doi:10.1002/uog.22034

36. Karami, P. et al. Mortality of a pregnant patient diagnosed with COVID-19: A case report with clinical, radiological, and histopathological findings. Travel Med. Infect. Dis. (2020). doi:10.1016/j.tmaid.2020.101665

37. Nie, R. et al. Clinical features and the maternal and neonatal outcomes of pregnant women with coronavirus disease 2019. (2020). doi:10.1101/2020.03.22.20041061

38. Lowe, B. \& Bopp, B. COVID-19 vaginal delivery - A case report. Aust. New Zeal. J. Obstet. Gynaecol. (2020). doi:10.1111/ajo.13173

39. Chen, S. et al. [Pregnant women with new coronavirus infection: a clinical characteristics and placental pathological analysis of three cases]. Zhonghua bing li xue za zhi = Chinese J. Pathol. (2020). doi:10.3760/cma.j.cn112151-20200225-00138

Page $7 / 15$ 
40. Li, Y. et al. Lack of vertical transmission of severe acute respiratory syndrome Coronavirus 2, China. Emerg. Infect. Dis. (2020). doi:10.3201/eid2606.200287

41. Fan, C. et al. Perinatal Transmission of COVID-19 Associated SARS-CoV-2: Should We Worry? Clin. Infect. Dis. (2020). doi:10.1093/cid/ciaa226

42. Zambrano, L. I. et al. A pregnant woman with COVID-19 in Central America. Travel Medicine and Infectious Disease (2020). doi:10.1016/j.tmaid.2020.101639

43. Iqbal, S. N. et al. An uncomplicated delivery in a patient with Covid-19 in the United States. New England Journal of Medicine (2020). doi:10.1056/NEJMc2007605

44. Wang, X. et al. A Case of 2019 Novel Coronavirus in a Pregnant Woman With Preterm Delivery. Clin. Infect. Dis. 71, 844-846 (2020).

45. Xiong, X. et al. Vaginal delivery report of a healthy neonate born to a convalescent mother with COVID-19. J. Med. Virol. jmv.25857 (2020). doi:10.1002/jmv.25857

46. Liu, Y., Chen, H., Tang, K. \& Guo, Y. Clinical manifestations and outcome of SARS-CoV-2 infection during pregnancy. J. Infect. (2020). doi:10.1016/j.jinf.2020.02.028

47. Li, Y. et al. Lack of Vertical Transmission of Severe Acute Respiratory Syndrome Coronavirus 2, China. Emerg. Infect. Dis. 26, 1335-1336 (2020).

48. Liu, W. et al. Clinical characteristics of 19 neonates born to mothers with COVID-19. Front. Med. (2020). doi:10.1007/s11684-020-0772-y

49. Lee, D. H. et al. Emergency cesarean section performed in a patient with confirmed severe acute respiratory syndrome Coronavirus-2 -a case report-. Korean J. Anesthesiol. 73, 347-351 (2020).

50. Yue, L. et al. Anaesthesia and infection control in cesarean section of pregnant women with coronavirus disease 2019 (COVID-19). 1-17 (2020). doi:10.1101/2020.03.23.20040394

51. Shi, H. et al. Radiological findings from 81 patients with COVID-19 pneumonia in Wuhan, China: a descriptive study. Lancet Infect. Dis. (2020). doi:10.1016/S1473-3099(20)30086-4

52. Liao, J. et al. Analysis of vaginal delivery outcomes among pregnant women in Wuhan, China during the COVID-19 pandemic. Int. J. Gynecol. Obstet. (2020). doi:10.1002/ijgo.13188

53. Yin, M. et al. Severe Acute Respiratory Syndrome Coronavirus 2 (SARS-CoV-2) Infection During Pregnancy In China: A Retrospective Cohort Study. 2, (2020).

54. Li, N. et al. Maternal and neonatal outcomes of pregnant women with COVID-19 pneumonia: a case-control study. Clin. Infect. Dis. (2020). doi:10.1093/cid/ciaa352

55. Shanes, E. D. et al. Placental Pathology in COVID-19. Am. J. Clin. Pathol. (2020). doi:10.1093/ajcp/aqaa089

56. Knight Dphil, M. et al. Characteristics and outcomes of pregnant women hospitalised with confirmed SARS-CoV-2 infection in the UK: a national cohort study using the UK Obstetric Surveillance System (UKOSS) The UK Obstetric Surveillance System SARS-CoV-2 Infection in Pregnancy Co. medRxiv 2020.05.08.20089268 (2020). doi:10.1101/2020.05.08.20089268

57. Govind, A. et al. Re: Novel Coronavirus COVID-19 in late pregnancy: Outcomes of first nine cases in an inner city London hospital. European Journal of Obstetrics and Gynecology and Reproductive Biology (2020). doi:10.1016/j.ejogrb.2020.05.004

58. Kayem, G. et al. A snapshot of the Covid-19 pandemic among pregnant women in France. J. Gynecol. Obstet. Hum. Reprod. 101826 (2020). doi:10.1016/j.jogoh.2020.101826

59. Wu, Y. et al. Coronavirus disease 2019 among pregnant Chinese women: case series data on the safety of vaginal birth and breastfeeding. BJOG An Int. J. Obstet. Gynaecol. (2020). doi:10.1111/1471-0528.16276

60. Nyholm, S. et al. Invasive mechanical ventilation in a former preterm infant with COVID-19. Acta Paediatr. apa.15437 (2020). doi:10.1111/apa.15437

61. Easterlin, M. C., De Beritto, T., Yeh, A. M., Wertheimer, F. B. \& Ramanathan, R. Extremely Preterm Infant Born to a Mother With Severe COVID19 Pneumonia. J. Investig. Med. High Impact Case Reports 8, 232470962094662 (2020).

62. Hong, L. et al. Severe COVID-19 infection in pregnancy requiring intubation without preterm delivery: A case report. Case Reports Women's Heal. 27, e00217 (2020).

63. Vivanti, A. J. et al. Transplacental transmission of SARS-CoV-2 infection. Nat. Commun. 11, 3572 (2020).

64. Salvatori, G. et al. Managing COVID-19-Positive Maternal-Infant Dyads: An Italian Experience. Breastfeed. Med. 15, 347-348 (2020).

65. Wu, Y.-T. et al. Neonatal outcome in 29 pregnant women with COVID-19: A retrospective study in Wuhan, China. PLOS Med. 17, e1003195 (2020).

66. Sisman, J. et al. INTRAUTERINE TRANSMISSION OF SARS-COV-2 INFECTION IN A PRETERM INFANT. Pediatr. Infect. Dis. J. Publish Ah, (2020). 
67. Yang, P. et al. Clinical characteristics and risk assessment of newborns born to mothers with COVID-19. J. Clin. Virol. 127, 104356 (2020).

68. Zheng, T. et al. Coronavirus disease 2019 (COVID-19) in pregnancy: 2 case reports on maternal and neonatal outcomes in Yichang city, Hubei Province, China. Medicine (Baltimore). 99, e21334 (2020).

69. Wang, S. et al. A Case Report of Neonatal 2019 Coronavirus Disease in China. Clin. Infect. Dis. 71, 853-857 (2020).

70. Yang, H., Hu, B., Zhan, S., Yang, L. \& Xiong, G. Effects of SARS-CoV-2 infection on pregnant women and their infants: A retrospective study in Wuhan, China. Arch. Pathol. Lab. Med. (2020). doi:10.5858/arpa.2020-0232-sa

71. Dumpa, V., Kamity, R., Vinci, A. N., Noyola, E. \& Noor, A. Neonatal Coronavirus 2019 (COVID-19) Infection: A Case Report and Review of Literature. Cureus (2020). doi:10.7759/cureus.8165

72. Masmejan, S. et al. Vertical transmission and materno-fetal outcomes in 13 patients with coronavirus disease 2019. Clin. Microbiol. Infect. (2020). doi:10.1016/j.cmi.2020.06.035

73. Hillary, H. et al. First case of placental infection with SARS-CoV-2. medRxiv (2020).

74. Ferraiolo, A. et al. Report of Positive Placental Swabs for SARS-CoV-2 in an Asymptomatic Pregnant Woman with COVID-19. Medicina (B. Aires). 56, 306 (2020).

75. Sisman, J. et al. Intrauterine Transmission of SARS-COV-2 Infection in a Preterm Infant. Pediatr. Infect. Dis. J. 39, e265-e267 (2020).

76. Ng, W. F. et al. The placentas of patients with severe acute respiratory syndrome: a pathophysiological evaluation. Pathology $38,210-218$ (2006).

77. Chen, S. et al. [Pregnant women with new coronavirus infection: a clinical characteristics and placental pathological analysis of three cases]. Zhonghua bing li xue za zhi = Chinese J. Pathol. 49, E005 (2020).

78. Zeng, H. et al. Antibodies in Infants Born to Mothers with COVID-19 Pneumonia. JAMA - Journal of the American Medical Association (2020). doi:10.1001/jama.2020.4861

79. Liu, D. et al. Pregnancy and Perinatal Outcomes of Women With Coronavirus Disease (COVID-19) Pneumonia: A Preliminary Analysis. AJR. Am. J. Roentgenol. (2020). doi:10.2214/AJR.20.23072

80. Zhu, H. et al. Clinical analysis of 10 neonates born to mothers with 2019-nCoV pneumonia. Transl. Pediatr. (2020). doi:10.21037/tp.2020.02.06

81. Lopes de Sousa, Á. F. et al. Effects of COVID-19 Infection during Pregnancy and Neonatal Prognosis: What Is the Evidence? Int. J. Environ. Res. Public Health 17, 4176 (2020).

82. Wang, W. et al. Detection of SARS-CoV-2 in Different Types of Clinical Specimens. JAMA - Journal of the American Medical Association (2020). doi:10.1001/jama.2020.3786

83. Chen, W. et al. Antibody response and viraemia during the course of severe acute respiratory syndrome (SARS)-associated coronavirus infection. J. Med. Microbiol. 53, 435-438 (2004).

84. Chin, A. M., Hill, D. R., Aurora, M. \& Spence, J. R. Morphogenesis and maturation of the embryonic and postnatal intestine. Semin. Cell Dev. Biol. 66, 81-93 (2017).

85. Zhou, Z. et al. The proprotein convertase furin is required for trophoblast syncytialization. Cell Death Dis. 4, 1-10 (2013).

86. Zhou, Z. et al. The proprotein convertase furin is required for trophoblast syncytialization. Cell Death Dis. 4, (2013).

87. D'Souza, R. et al. A critical review of the pathophysiology of thrombotic complications and clinical practice recommendations for thromboprophylaxis in pregnant patients with COVID-19. Acta Obstet. Gynecol. Scand. 1-11 (2020). doi:10.1111/aogs.13962

88. Zhang, D. et al. COVID-19 infection induces readily detectable morphological and inflammation-related phenotypic changes in peripheral blood monocytes, the severity of which correlate with patient outcome. (2020). doi:10.1101/2020.03.24.20042655

89. Cohn, J. N., Ferrari, R. \& Sharpe, N. Cardiac remodeling-concepts and clinical implications: a consensus paper from an international forum on cardiac remodeling. Behalf of an International Forum on Cardiac Remodeling. J Am Coll Cardio/ 35, 569-82 (2000).

90. yang, H. et al. Clinical features and outcomes of pregnant women suspected of coronavirus disease 2019. J. Infect. (2020). doi:10.1016/j.jinf.2020.04.003

\section{Tables}

Table1: Reported cases of vertical transmission, clinical manifestations and placental abnormalities in SARS-1, HKCoV and MERS

Abbreviations: HKCoV: Hong Kong Coronaviridae, MERS: Middle East Respiratory Syndrome, NEC: Necrotizing enterocolitis, RDS: Respiratory Distress Syndrome, SARS: Severe acute respiratory syndrome. 


\begin{tabular}{|c|c|c|c|c|c|c|c|c|c|c|}
\hline Paper & $\begin{array}{c}\text { Wong et } \\
\mathrm{al}^{3}\end{array}$ & $\begin{array}{l}\text { Robertson } \\
\text { et al }{ }^{10}\end{array}$ & $\begin{array}{l}\text { Yudin } \\
\text { et al }{ }^{4}\end{array}$ & $\begin{array}{l}\text { Stockman } \\
\text { et al }^{5}\end{array}$ & $\begin{array}{c}\text { Gagneur et } \\
\text { al }^{6}\end{array}$ & $\begin{array}{c}\text { Shek et } \\
\mathrm{al}^{8}\end{array}$ & Li et al ${ }^{7}$ & $\underset{1}{\text { Jeong et al }}$ & $\begin{array}{l}\text { Payne } \\
\text { et al }{ }^{2}\end{array}$ & Totals \\
\hline Outbreak & SARS-1 & SARS-1 & $\begin{array}{c}\text { SARS- } \\
1\end{array}$ & MERS & HKCoV/SARS & SARS-1 & SARS-1 & MERS & MERS & \\
\hline $\begin{array}{c}\text { Number of } \\
\text { Studied } \\
\text { Mother-Infant } \\
\text { pairs }\end{array}$ & 12 & 1 & 1 & 2 & 7 & 5 & 41 & 1 & 1 & 71 \\
\hline $\begin{array}{c}\text { Number of } \\
\text { Neonates } \\
\text { with vertical } \\
\text { transmission }\end{array}$ & 0 & 0 & 0 & 0 & 2 & 0 & 0 & 0 & 0 & $\begin{array}{c}2 / 71 \\
(2.8 \%)\end{array}$ \\
\hline $\begin{array}{c}\text { Reported } \\
\text { Complications } \\
\text { In Neonates } \\
\text { (whether with } \\
\text { positive or } \\
\text { negative } \\
\text { swabs ) }\end{array}$ & $\begin{array}{l}\text { 2: NEC } \\
1: \text { RDS }\end{array}$ & 0 & 0 & 0 & $\begin{array}{l}\text { 2: Still birth } \\
\text { with fetal } \\
\text { deceleration }\end{array}$ & 2: NEC & 0 & 0 & $\begin{array}{c}1: \\
\text { Still } \\
\text { birth }\end{array}$ & $\begin{array}{c}\text { RDS: } \\
1 / 71 \\
(1.4 \%) \\
\text { Still } \\
\text { birth: } \\
3 / 71 \\
(4.2 \%) \\
\text { NEC: } \\
4 / 71 \\
(5.6 \%)\end{array}$ \\
\hline $\begin{array}{c}\text { Reported } \\
\text { Placental } \\
\text { abnormalities }\end{array}$ & $\begin{array}{c}1: \\
\text { Placental } \\
\text { infarction }\end{array}$ & 0 & 0 & 0 & 0 & $\begin{array}{c}\text { Not } \\
\text { Reported }\end{array}$ & $\begin{array}{c}\text { Not } \\
\text { reported }\end{array}$ & $\begin{array}{l}\text { 2: Placental } \\
\text { infarction }\end{array}$ & 0 & $\begin{array}{c}3 / 25 \\
(12 \%)\end{array}$ \\
\hline
\end{tabular}


Table 2: References used to construct Table 3, 4, 5 about Neonatal and maternal outcome of COVID-19

\begin{tabular}{|c|c|}
\hline Reference & Location \\
\hline Lowe e Bopp ${ }^{38}$ & Australia \\
\hline Kirtsman et al. ${ }^{30}$ & Canada \\
\hline Fan et al. 41 & China \\
\hline Chen et al. ${ }^{25}$ & China \\
\hline Li et al. 40 & China \\
\hline Lee et al. 49 & China \\
\hline Xiaotong et al. ${ }^{44}$ & China \\
\hline Kang et al. ${ }^{31}$ & China \\
\hline Lu et al. ${ }^{33}$ & China \\
\hline Liao et al. ${ }^{28}$ & China \\
\hline Buonsenso et al. ${ }^{32}$ & China \\
\hline Khan et al. ${ }^{34}$ & China \\
\hline Dong et al. ${ }^{49}$ & China \\
\hline Xiong et al. 45 & China \\
\hline Liu et al. ${ }^{46}$ & China \\
\hline Chen et al. 77 & China \\
\hline Yu et al. ${ }^{29}$ & China \\
\hline Zeng et al. ${ }^{78}$ & China \\
\hline Chen, Liao and Shao ${ }^{77}$ & China \\
\hline Liu et al. ${ }^{27}$ & China \\
\hline Zhu et al. ${ }^{80}$ & China \\
\hline Chen et al. ${ }^{39}$ & China \\
\hline Chen et al. ${ }^{83}$ & China \\
\hline Nie et al. ${ }^{37}$ & China \\
\hline Khan et al. ${ }^{14}$ & China \\
\hline Qianchenga et al. ${ }^{26}$ & China \\
\hline
\end{tabular}




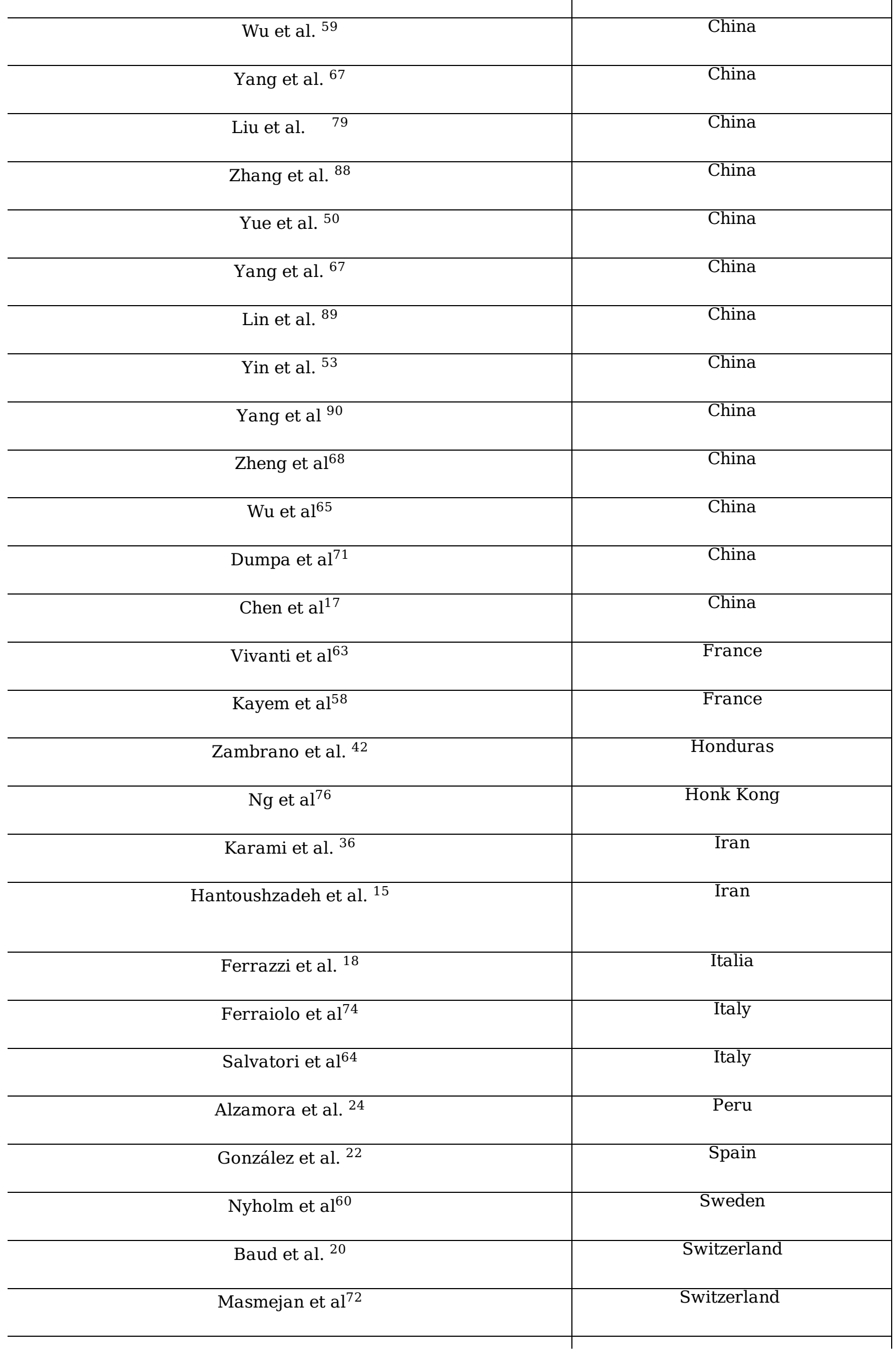




\begin{tabular}{c|c|} 
Kalafat et al. $^{35}$ & Turkey \\
\hline${\text { Govind et } \text { al }^{57}}$ & UK \\
\hline Knight et al $^{56}$ & UK \\
\hline Breslin et al. $^{23}$ & USA \\
\hline Shanes et al. $^{55}$ & USA \\
\hline Iqbal et al. $^{43}$ & USA \\
\hline Hillary et al $^{73}$ & USA \\
\hline Hong et al ${ }^{62}$ & USA \\
\hline Sisman et al ${ }^{66}$ & USA \\
\hline Easterlin et al ${ }^{61}$ & USA \\
\hline
\end{tabular}

Abbreviations: UK: United Kingdom, USA: United States of America

Table 3 


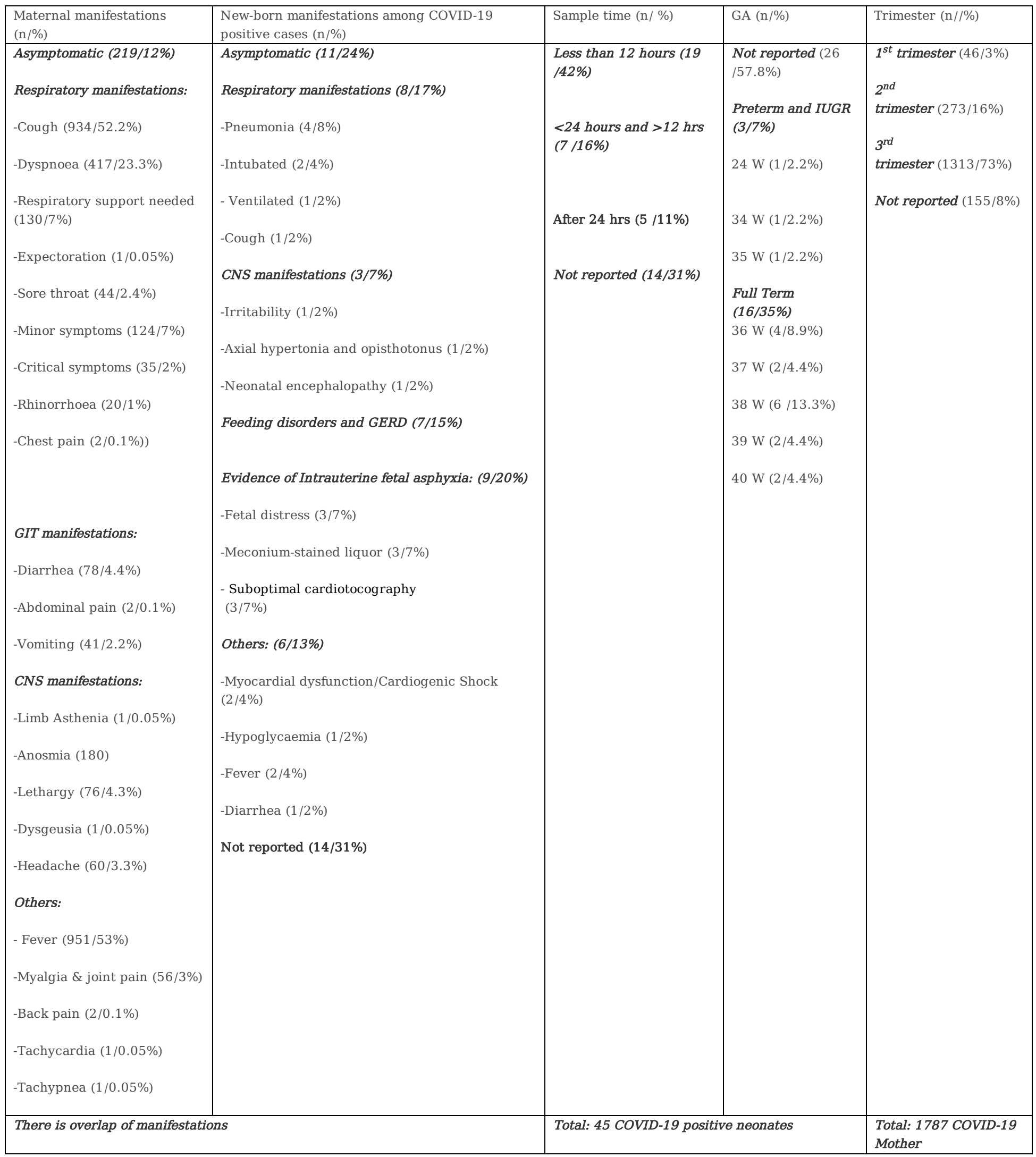

COVID-19: Coronaviridae, CNS: Central Nervous System, GA: Gestational Age, GERD: Gastroesophageal reflux, IUGR: Intrauterine Growth retardation

Table 4: Placental abnormalities in placentae of COVID-19 positive mothers in retrieved studies 


\begin{tabular}{|c|c|c|c|}
\hline Type of Placental Abnormalities & $\begin{array}{r}\text { Number } \\
(\mathrm{n})\end{array}$ & $\begin{array}{l}\text { Percentage of abnormalities to Total } \\
\text { number of abnormal placentae }\end{array}$ & $\begin{array}{r}\text { Percentage of abnormalities to } \\
\text { Total number of examined } \\
\text { placentae }\end{array}$ \\
\hline \multicolumn{4}{|c|}{ Changes in Placental weight } \\
\hline Small Placenta & 3 & 6.7 & 1.0 \\
\hline Large Placenta & 1 & 2.2 & 0.3 \\
\hline \multicolumn{4}{|c|}{ Microscopic Changes } \\
\hline Delayed maturation of villous tree & 1 & 2.2 & 0.3 \\
\hline $\begin{array}{l}\text { Terminal villi (capillary } \\
\text { congestion and focal } \\
\text { microchrangiosis) }\end{array}$ & 1 & 2.2 & 0.3 \\
\hline Villous agglutination & 1 & 2.2 & 0.3 \\
\hline $\begin{array}{l}\text { Multiple organizing intervillous } \\
\text { hemorrhage /thrombi }\end{array}$ & 4 & 8.9 & 1.3 \\
\hline Chronic intervillositis & 3 & 6.7 & 1.0 \\
\hline Funisitis & 1 & 2.2 & 0.3 \\
\hline $\begin{array}{l}\text { Infiltration with Inflammatory } \\
\text { cells }\end{array}$ & 4 & 8.9 & 1.3 \\
\hline Defective placental barrier & 7 & 15.6 & 2.2 \\
\hline Fibrosis/avascular villi & 20 & 44.4 & 6.3 \\
\hline $\begin{array}{l}\text { Placental Swab positive for SARS } \\
\text { CoV-2 }\end{array}$ & 17 & 37.8 & 5.4 \\
\hline $\begin{array}{l}\text { Total number of Placentae found } \\
\text { with abnormalities }\end{array}$ & 46 & & 14.3 \\
\hline $\begin{array}{l}\text { Total Number of examined } \\
\text { placentae }\end{array}$ & 315 & & \\
\hline
\end{tabular}

Table 5: Laboratory abnormalities in COVID-19 POSITIVE NEONATES

\begin{tabular}{|l|r|r|}
\hline & Number & Percentage \\
\hline No. of neonates positive for COVID-19 & 45 & 100 \\
& & \\
& & \\
\hline Leukocytosis & 6 & 13.3 \\
\hline Leucopenia & 5 & 11.1 \\
\hline Neutrophilia & 3 & 6.7 \\
\hline Lymphopenia & 9 & 20.0 \\
\hline Reticulocytosis & 1 & 2.2 \\
\hline CRP & 2 & 4.4 \\
\hline Elevated Prothrombin Time & 3 & 6.7 \\
\hline Elevated Ferritin & 1 & 2.2 \\
\hline Elevated AST & 4 & 8.9 \\
\hline Elevated ALT & 2 & 4.4 \\
\hline Elevated Bilirubin total & 3 & 7.7 \\
\hline Elevated Indirect bilirubin & 1 & 2.2 \\
\hline Elevated IL-6 & 3 & 6.7 \\
\hline Elevated IL-10 & 1 & 2.2 \\
\hline
\end{tabular}

ALT: Alanine Aminotransferase, AST: Aspartate Aminotransferase, COVID-19: Coronavirus Disease 2019, CRP: C-Reactive protein, IL: interleukin. 